\title{
The development of an RC-network simulation model calibrated with monitoring data for use in the performance guarantee of Net-Zero houses
} \author{
and Edwin van Kessel ${ }^{4}$ \\ ${ }^{1}$ TNO, Department of Building Physics and Systems, Delft, the Netherlands \\ ${ }^{2}$ BAM Bouw en Techniek, Bunnik, the Netherlands \\ ${ }^{3}$ van Wijnen Midden, Harderwijk, the Netherlands \\ ${ }^{4} \mathrm{BeNext}$, Amsterdam, the Netherlands
}

Marleen Spiekman ${ }^{1, *}$, Olav Vijlbrief ${ }^{1}$, Haseeb Tahir ${ }^{1}$, Yasin Bulut ${ }^{1}$, Wouter Borsboom ${ }^{1}$, T.A.J. van Goch ${ }^{2}$, Dick van Ginkel ${ }^{3}$

\begin{abstract}
In order to drive forward the energy transition, construction companies and other suppliers of deep retrofitting solutions have started to give guarantees on the energy performance of very energy efficient houses. With these initiatives, a need has arisen for methods that can assess per household the actual energy performance during the use phase. An RC-network simulation model calibrated with monitoring data has been developed and tested on deep retrofitted Net-Zero houses in Emmen (the Netherlands). The results show that this has been a successful first step in order to arrive at a realistic analysis of the actual energy performance of individual houses. The big challenge will be to determine the parameters in the model with more certainty. This applies especially, but not exclusively, to the behavioural parameters.
\end{abstract}

\section{Introduction}

In order to drive forward the energy transition, stakeholders are looking for ways to accelerate the construction and renovation towards highly energyefficient buildings that go far beyond the current regulatory bottom-line requirements. To stimulate interest from owners and tenants, construction companies and other suppliers of deep retrofitting solutions have started to give guarantees on the energy performance of these houses [1] and want to do the same for comfort and health related aspects in the future.

With these initiatives, a need has arisen for methods that can test these performances in practice. For various reasons, the performance may be disappointing (See [2] for a review). The person who provides the guarantee, sometimes for 25 years, can be held accountable if the guarantee is not met. This is justified if a disappointing performance is caused by structural or technical installation defects. In practice, however, we see that user behaviour also has a major impact on the performance of a house. In any case, we want insight into the cause of disappointing performances: if an installation is not properly set up or tuned, you want to send an installation engineer to the house as soon as possible, and if a resident's behaviour is the cause of high energy consumption, you may want to send an energy coach. Also, insight is needed in user interaction to select and improve concepts that perform better during actual use, using such insights in a proactive way to optimise design, operation and utilization. That's why we want to develop a method with which we can determine at an individual level the actual performance of houses that are in use.

\section{Method}

\subsection{General approach}

The route we are following is to develop a simulation model calibrated with monitoring data of Net-Zero houses that allows us to approach the actual performance of energy efficient houses on an individual level. Compared to conventional monitoring of Net-Zero houses in the Netherlands, the monitoring has been extended with sensors that monitor aspects of energy related user behaviour. The development of the method involves roughly three steps: 1) gathering data on energy use and user behaviour in energy efficient houses for at least one year, 2) development of the model and 3) estimation of the parameters in the model.

The ultimate goal is to be able to determine the parameters in the model with such certainty that the model provides a good description of reality. This technical paper describes the first step of this development towards a reliable estimation. The aim of this step is not to come to a scientifically sound methodology, but to see if we are able to make a model calibrated with monitoring data that resembles the actual

\footnotetext{
* Corresponding author: marleen.spiekman@tno.nl
} 
performance as good as possible and define which next steps can improve the certainty of the method.

\subsection{Monitoring}

For the development of the method, we started with data gathering in 4 houses in Emmen, a city in the north-east of the Netherlands. The houses are located in a neighbourhood with social housing, originally built around 1970 and recently renovated to the Net-Zero level. Within the Net-Zero concept, the houses are renovated to become net-zero-energy using an industrialised (pre-manufactured) concept that includes a full refurbishment of the thermal shell, installations and the deployment of local generation. Glassing is replaced, a new façade is placed and additional insolation is applied on the roof and ground floor. Energy efficient installations are included in an energy module that provides heating (air/water heat pump), fresh air (RCU), storage (Sensible/Water) and connectivity. Solar panels, a heat recovery system and a heat pump are installed. Each dwelling has 2 floors. The living room and the kitchen are located on the ground floor. On the first floor, 3 bedrooms and the bathroom can be found. The dwelling has a flat roof.

In each of the dwellings, a set of sensors and a gateway was installed to monitor the energy use, the temperature, but also if doors and windows are open or closed. In Table 1 an overview of the sensors is given, including the location in the dwellings. All data was gathered hourly.

Table 1. Overview of the sensors in the dwellings.

\begin{tabular}{|l|l|}
\hline Sensor type & Location \\
\hline Temperature $\left[{ }^{\circ} \mathrm{C}\right]$ & Living room \\
\hline Temperature $\left[{ }^{\circ} \mathrm{C}\right]$ & Kitchen \\
\hline Temperature $\left[{ }^{\circ} \mathrm{C}\right]$ & Main bedroom \\
\hline Temperature $\left[{ }^{\circ} \mathrm{C}\right]$ & Bedroom 2 \\
\hline Temperature $\left[{ }^{\circ} \mathrm{C}\right]$ & Bedroom 3 \\
\hline Temperature $\left[{ }^{\circ} \mathrm{C}\right]$ & Living room neighbourgs 1 \\
\hline Temperature $\left[{ }^{\circ} \mathrm{C}\right]$ & Living room neighbourgs 2 \\
\hline Setpoint $\left[{ }^{\circ} \mathrm{C}\right]$ & Living room \\
\hline Setpoint $\left[{ }^{\circ} \mathrm{C}\right]$ & Main bedroom \\
\hline Energy $[\mathrm{W}]$ & Heat pump \\
\hline Energy $[\mathrm{W}]$ & Heat recovery system \\
\hline Energy $[\mathrm{W}]$ & Solar panels \\
\hline Energy $[\mathrm{W}]$ & Smart Meter \\
\hline Status $[-]$ & $\begin{array}{l}\text { Heat pump (in use for space } \\
\text { heating or domestic hot } \\
\text { water) }\end{array}$ \\
\hline Open/Close $[-]$ & Front door \\
\hline Open/Close $[-]$ & Back door \\
\hline Open/Close $[-]$ & Kitchen window \\
\hline Open/Close $[-]$ & Living room window \\
\hline Open/Close $[-]$ & Main bedroom window \\
\hline Open/Close $[-]$ & Bedroom 2 window \\
\hline
\end{tabular}

\begin{tabular}{|l|l|}
\hline Open/Close [-] & Bedroom 3 window \\
\hline \multicolumn{2}{|c|}{ In addition, we visited the houses and measured the }
\end{tabular} mechanical ventilation flows (in $\left[\mathrm{dm}^{3} / \mathrm{s}\right]$ ) and the airtightness (in $\left[\mathrm{dm}^{3} / \mathrm{s}^{2} \mathrm{~m}^{2}\right]$ at $10 \mathrm{~Pa}$ pressure difference). And we estimated weekly occupancy patterns for each household based on questionnaire data. For the development of the model we started with data of 2 of the 4 houses in Emmen of which we had the most and qualitative best data. In this report, we will call these houses 'Emmen 1" and "Emmen 2".

\subsection{Modelling}

For the simulation model of the dwellings in Emmen, we chose an hourly 3-zone RC-network model as a basis. This choice was made because the RC-network simulation model needs to do justice to the dynamics on the one hand, but not contain too many parameters on the other hand to prevent overfitting. Therefore simple models, such as a monthly model, and detailed models with many parameters, such as frequently used in energy simulation software as TRNSYS, were rejected. We made the choice for more zones to be able to distinguish among spaces that are used and heated differently. Originally we divided the houses over the zones as follows: zone 1 is the heated living room and kitchen (the whole ground floor), zone 2 are all heated spaces and zone 3 all unheated spaces on the first floor. However, in both houses in Emmen all rooms on the first floor were either all heated or all unheated. For future use we decided to stick to 3 zones and the distinction between zone 2 and 3 was finally made based on orientation. The RC-network used is given in Figure 1, which shows the RC-network for zone 1 in detail. The RC-networks for zone 2 and 3 are similar, with the exception of the losses through the ground floor.

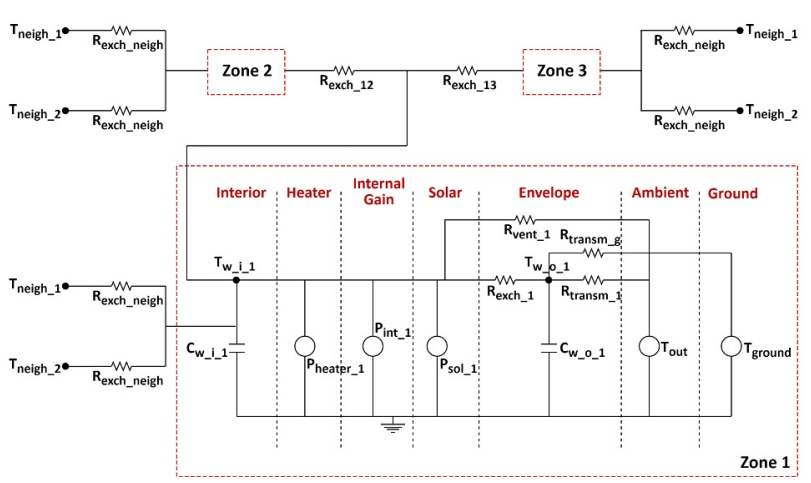

Fig. 1. Scheme of the RC-network used for zone 1.

The RC-network has two state variables for each zone, one describing the interior temperature $T_{\mathrm{w}_{-} \mathrm{i}}\left(T_{\mathrm{w}_{-} \mathrm{i} 1} 1\right.$ for Zone 1), which is the lumped temperature of indoor air and the first layer of the wall and one representing the temperature of the building envelope $T_{\mathrm{w}_{-} \mathrm{o}}\left(T_{\mathrm{w} \_\mathrm{o} \_}\right.$for Zone 1). The first-order dynamics are represented by the differential equations below for Zone 1 .

$$
\begin{array}{r}
\mathrm{d} T_{\mathrm{w} \_\mathrm{i} \_1} / \mathrm{d} t=\left(1 / C_{\mathrm{w} \_\mathrm{i} \_1}\right)\left(-P_{\text {exch_1 }}+P_{\text {vent_1 }}+P_{\text {sol_1 }} 1\right. \\
\left.+P_{\text {int_ } 1}+P_{\text {exch_12 }}+P_{\text {exch_13 }}+P_{\text {neigh_1 }}+P_{\text {neigh_2 }}\right)
\end{array}
$$




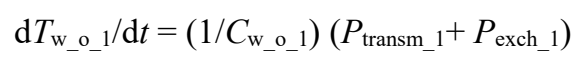

where,

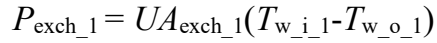

$$
\begin{aligned}
& P_{\text {vent_1 }}=U A_{\text {vent_1 }}\left(T_{\text {out }}-T_{\text {w__ } 11}\right) \\
& P_{\text {sol_1 }}=\left(g_{\text {window }}\right)\left(\bar{f}_{\text {shading }}\right)\left(Q_{\text {sol }}\right)\left(A_{\text {window_ } 1}\right)\left(f_{\text {solar fraction }}\right)(5) \\
& P_{\text {transm } \_1}=U A_{\text {transm_1 } 1}\left(T_{\text {out }}-T_{\text {w_o } 11}\right) \\
& +U A_{\text {transm_g }}\left[\left(T_{\text {ground }}-T_{\text {out }}\right) / 2-T_{\text {w_o } \_1}\right] \\
& P_{\text {exch_12 }}=U A_{\text {exch_12 }}\left(T_{\mathrm{w} \_ \text {i } 2-}-T_{\text {w_i } \_1}\right) \\
& P_{\text {exch_13 }}=U A_{\text {exch_13 }}\left(T_{\text {w__ } 33}-T_{\text {w_i } 11}\right) \\
& P_{\text {neigh_1 }}=U A_{\text {neigh_1 }}\left(T_{\text {neigh_1 }}-T_{\mathrm{w} \text { _ } 11}\right) \\
& P_{\text {neigh_2 }}=U A_{\text {neigh_2 }}\left(T_{\text {neigh_2 }}-T_{\text {w__ } \_1}\right)
\end{aligned}
$$

The state equations above do not include the power of the heating system of zone $1\left(P_{\text {heater_l }}\right)$. This parameter is determined per time step as follows: 1) temporary temperatures are calculated by the state equations, 2) the required heating power for each zone is calculated based on the setpoint temperatures, the temporary temperatures and the maximum capacity of the heating system (a heat pump), 3) the heating capacity is evenly distributed based on the heating needs in each zone, and finally 4), the temperatures in the next time step are calculated based on the adjusted heating powers for each zone.

\subsection{Model parameters}

\subsubsection{Building parameters}

Main source of the estimated values of the parameters used in the model was the construction company that has renovated the houses towards Net-Zero. The information they provided included: floor areas, construction areas, insulation values of all opaque elements and doors and windows, construction materials and system types used. The building mass was estimated based on the volume and density of the building materials. The fraction between the indoor mass and the total building mass is assumed as 0,3 for a medium level insulated singlefamily house, following the method used in [3]. Table 2 gives an overview of building parameters used in the RC-network model for Emmen 1.

Table 2. Overview of the building parameters used.

\begin{tabular}{|l|l|}
\hline Parameters & Emmen 1 \\
\hline Total Floor Area $\left[\mathrm{m}^{2}\right]$ & 120 \\
\hline Floor Height $[\mathrm{m}]$ & 5.5 \\
\hline Window Area $\left[\mathrm{m}^{2}\right]$ & 23.1 \\
\hline Rc Floor $\left[\mathrm{m}^{2} \mathrm{~K} / \mathrm{W}\right]$ & 5 \\
\hline Rc Façade $\left[\mathrm{m}^{2} \mathrm{~K} / \mathrm{W}\right]$ & 4.7 \\
\hline Rc Roof $\left[\mathrm{m}^{2} \mathrm{~K} / \mathrm{W}\right]$ & 5 \\
\hline Window $\mathrm{U}$ value $\left[\mathrm{W} / \mathrm{m}^{2} \mathrm{~K}\right]$ & 1.1 \\
\hline Infiltration Rate $(\mathrm{q} 10)\left[\mathrm{dm}^{3} / \mathrm{s}^{2} \mathrm{~m}^{2}\right]$ & 1 \\
\hline
\end{tabular}

\subsection{Heating system}

The hourly value of the COP of the heat pump is based on the datasheet with the measured performance by the manufacturer. The data was verified for one house by measurements of the consumed power of the heat pump and the delivered heat (flow rate and temperatures). The maximum heating capacity of the heat pump is $5 \mathrm{~kW}$.

\subsubsection{Ventilation and infiltration}

The mechanical ventilation flows were measured using a flow finder for all settings. The setting of the ventilation system (low, medium or high) was measured indirectly by measuring the power of the ventilation system. The airtightness of the houses was measured using the new airtightness measuring method, the AirTightnessTester, described in [4]. Flow rates through open windows and doors were estimated using measurements of window and door opening and wind velocity. All windows and outdoor doors were equipped with a sensor that measured whether it was opened or closed. Via a questionnaire, it was estimated how far the windows and doors were opened (the fraction of window opening).

\subsubsection{Internal gains}

The internal heat gain of lighting and appliances was derived from the electricity measurements with an assumed correction factor of $90 \%$ to take into account that a small part of the electricity used will not transfer into internal gains. The internal gains from occupants were estimated using a questionnaire, where occupants gave an average presence pattern for all persons living in the house.

\subsubsection{Temperatures and weather}

The setpoint temperature in the living room was measured, as well as the indoor temperature at the neighbour's living room on both sides. These measured values were used as input parameters in the model. The outdoor temperature, wind velocity and the hourly solar radiation on the horizontal surface were obtained from a weather station approximately $25-30 \mathrm{~km}$ away, in Hoogeveen. The ground temperature was unknown. The ground floor has a natural ventilated crawlspace, therefore the hourly ground temperature for the transmission losses through the ground floor was estimated as the average value of the outdoor temperature and an estimated constant ground temperature of $10^{\circ} \mathrm{C}$.

\subsubsection{Parameter tuning}

Part of measured parameters (the indoor temperatures of Emmen 1 and the heating power) were used to verify 
whether the modeled results are in close agreement with reality. The only parameter we used for tuning was the window opening fraction. The fraction of window opening, being an unknown parameter, was tuned to match the model results as good as possible. The process was done by hand in a few steps. The end result of this process is described in section 3 .

\section{Results}

The RC-network model is run with a one-hour simulation time step for the whole measurement period, starting from 22 September 2017 until 28 May 2018. This period covers almost the whole space heating period throughout the year. For a model to be suitable there should be close agreement between the predicted and the measured data. To investigate whether the parameter tuning was successful we used 3 indicators: 1) the actual energy consumption, 2) the actual hourly temperature changes in the different zones for the measurement period and 3) the energy signatures. If the model is able to closely follow the 3 indicators, including the hourly pattern of the temperatures in the zones, this gives some confidence that the model represents reality.

The results are given in figures 2 to 4 for Emmen 1. The results for Emmen 2 are quite similar. Figure 2 shows the measured and calculated temperatures in the 3 zones for Emmen 1 and the ambient temperature. Zone 1 is heated in winter and zone 2 and 3 are unheated. The predicted temperature for all 3 zones is following the measured temperature reasonably well.
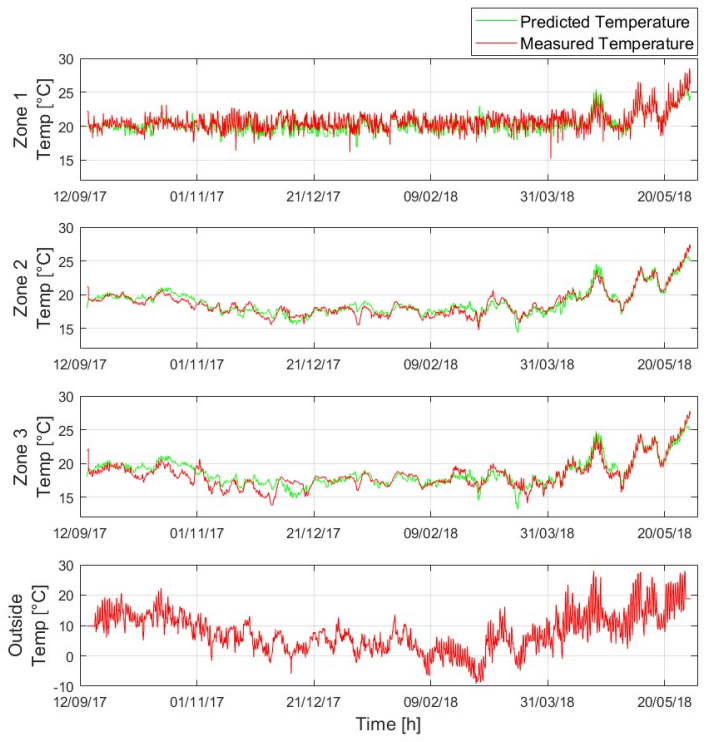

Fig. 2. Calculated and measured temperature results for Emmen 1 per zone and ambient temperature.

Figure 3 shows the cumulative heating demand of Emmen 1 for the above-mentioned time period. In this plot, the result of the RC-network model (Predicted Heating) is compared to the measured heating demand of
Emmen 1. Since the measurement period starts in September, the heating required at the beginning of the simulation period is low. The RC-network model estimates a total heating demand of $5244 \mathrm{kWh}$, which is comparable with the measured heating demand (5301 $\mathrm{kWh}$ ).

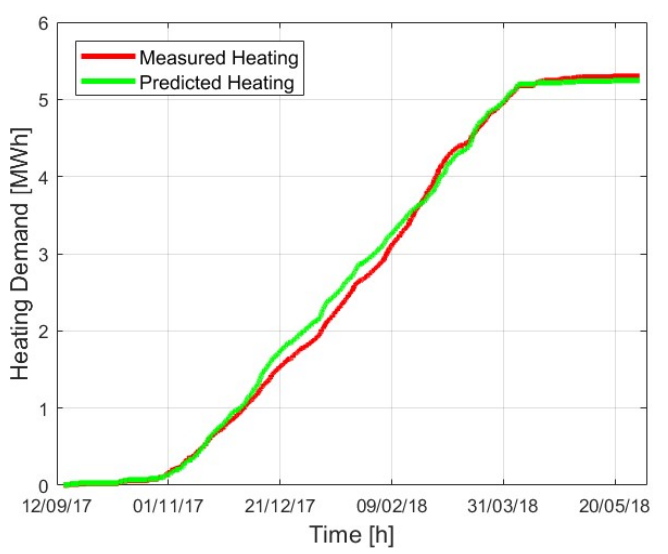

Fig. 3. Calculated and measured cumulative heating demand for Emmen 1.

An energy signature represents the heating demand versus the ambient temperature which is averaged over a defined period, typically a week. The slope of the lines in an energy signature represents the total losses. The higher the slope, the higher will be the losses and consequently the heating demand of the dwelling. Figure 4 shows the energy signature of Emmen 1 for the abovementioned time period. In the plot, the calculated energy use with the RC-network model (Predicted Power) is compared to the measured energy use (Measured Power) of the house. The energy demand and the outside temperature is averaged on weekly-basis. The red and green dots (o and $\mathrm{x}$ respectively) in the figure represent the measured and predicted data points, respectively and the red and green lines represent the linear regression of the corresponding data points. The predicted results for the energy signature is in quite close agreement with the measured energy signatures.

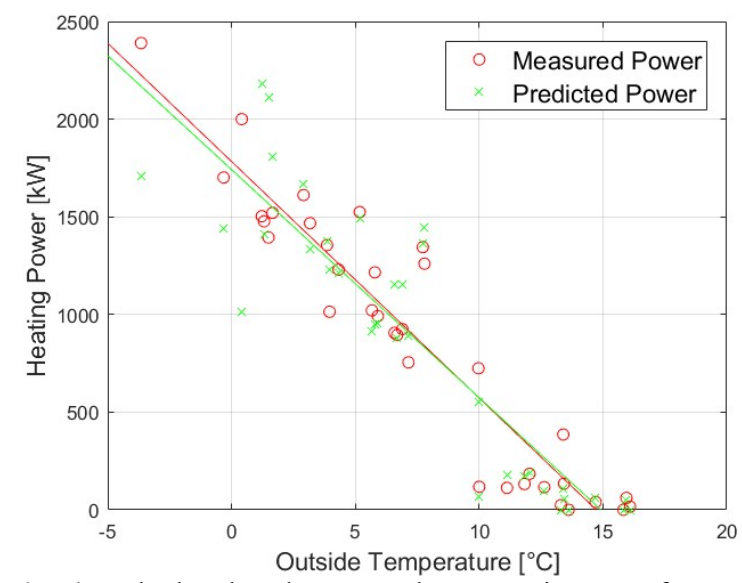

Fig. 4. Calculated and measured energy signature for Emmen 1. 


\section{Discussion}

We were able to tune the model in such a way that the calculated temperatures in the 3 zones, as well as the cumulative heating demand, as well as the energy signature followed the measured values reasonably well. The fact that the model is able to follow these 3 indicators, gives some confidence that the model actually represents reality. However, the fit techniques are not yet of such a nature that we can be completely sure that the parameters are close to the actual characteristics.

The only parameter we used for tuning was the window opening fraction. Because many parameters are insecure, we didn't run an optimization, since that would be pretended accuracy. Measurement of the window opening fraction is possible, but probably not feasible in practice. We need sophisticated techniques to estimate the parameters of the model more accurately. A more sophisticated ventilation model might also help to incorporate the airflow through the windows and doors based on the dynamic weather conditions (wind speed and wind direction). In addition, it is also important to consider the air coupling among the different zones.

\section{Conclusion}

What the study has shown is that it is feasible to fit a model to monitoring data and to arrive at a good reflection of the actual energy consumption, hourly temperature progression, and energy signature. This has been achieved despite the fact that the spread in the user behaviour of residents and neighbours, in particular, leads to large variations in these factors. On the other hand, we reached these results thanks to the fact that we have been able to map out this behaviour through monitoring and surveys.

We can conclude that setting up an RC-network simulation model of the first Net-Zero houses has been a successful first step in order to arrive at a realistic analysis of the performance guarantee of individual houses. The big challenge will be to determine the parameters in the model with more certainty. This applies especially, but not exclusively, to the behavioural parameters.

\section{Next steps}

There are a number of methods that will help us to get more certainty about the parameters in the model. Some of these methods are already being concretely developed in follow-up projects, or will be taken up in future proposals:

- Using a probabilistic model to get more certainty about the parameter estimation: to get insight into the effect of the uncertainty of all parameters in the RC-network simulation model, we are working on a probabilistic model. Instead of using estimated values in the model, we use probability curves based on literature sources or directly derived from data.

- Using Artificial Intelligence (AI) to predict parameters from measured data: We have done a first study to see whether we could predict the use of windows and doors based on the measured data. The results were promising: we were able to predict if a window was open or closed with an accuracy of $80 \%$ for all hours of the year. This prediction was done for 2 of the houses in Ermelo with an algorithm that was trained by 2 other houses in Ermelo. We plan to expand the study next year and also study where AI (hybrid models) have an added value to models solely based on physics.

- Using fault diagnoses to infer if building components or systems malfunction: In previous projects, we focused on fault diagnoses based on monitoring data, but mainly in non-residential buildings. These techniques can also be adapted to houses; what are common faults and what are typical patterns in monitoring data due to these faults.

- Using parameter identification by grey box modelling: Fitting parameters using grey box modelling is a technique that combines physical models with statistical models. The technique is proven for models with only a few parameters. A research question is whether the technique will work in more complex models.

- Using physical models to estimate parameters: One of the key parameters in a building model is the building mass. Estimating the building mass from night set back profiles is relatively easy for office buildings and older houses with clear temperature drops at night. However, for Net-Zero houses this proves more difficult since the temperature drop at night is quite small. There might be other ways to do this, e.g. by looking for holiday periods or using free floating temperatures in summer.

- Using a better model to estimate ventilation flows: a parameter with a large influence is the ventilation flow due to open windows. By coupling a more detailed ventilation model (COMIS) to the RC-network, we might be able to estimate this component more realistically. With this module added to the RCnetwork, it will also be possible to take into account the actual indoor air quality performance in addition to actual energy performance and actual thermal comfort performance.

This work was part of the Dutch project TKI Optimaal and cofunded by TKI Urban Energy from the Surcharge for Top Consortia for Knowledge and Innovation (TKIs) of the Ministry of Economic Affairs of the Netherlands.

\section{References}

1. H. Bekkema, I. Opstelten, Marktmonitor nul-op-demeter. Stroomversnelling (2019)

2. P.X.W. Zou, X. Xu, J. Sanjayan, J. Wang, Energy and Buildings 178, 165-181 (2018)

3. F. Koene, L. Bakker, D. Lanceta, S. Narmsara, Proc. of the $5^{\text {th }}$ German-Austrian IBPSA Conference, $p$ 152-159 (2014)

4. T. Lanooy, N.-J. Bink, W. Kornaat, W. Borsboom, Proc. of the $40^{\text {th }}$ AIVC Conference (2019) 


\section{Nomenclature}

\begin{tabular}{|c|c|c|}
\hline$T_{\mathrm{w} \_ \text {i_ } 1}$ & $\begin{array}{l}\text { Interior temperature/inner thermal } \\
\text { mass temperature of zone } 1\end{array}$ & {$\left[{ }^{\circ} \mathrm{C}\right]$} \\
\hline$T_{\mathrm{w}_{-} \mathrm{i} \_2}$ & $\begin{array}{l}\text { Interior temperature/inner thermal } \\
\text { mass temperature of zone } 2\end{array}$ & {$\left[{ }^{\circ} \mathrm{C}\right]$} \\
\hline$T_{\mathrm{w} \_ \text {i_ } 3}$ & $\begin{array}{l}\text { Interior temperature/inner thermal } \\
\text { mass temperature of zone } 3\end{array}$ & {$\left[{ }^{\circ} \mathrm{C}\right]$} \\
\hline$T_{\mathrm{w} \_ \text {o_}} 1$ & Outer mass temperature of zone 1 & {$\left[{ }^{\circ} \mathrm{C}\right]$} \\
\hline$T_{\text {out }}$ & Ambient temperature & {$\left[{ }^{\circ} \mathrm{C}\right]$} \\
\hline$T_{\text {ground }}$ & Ground temperature & {$\left[{ }^{\circ} \mathrm{C}\right]$} \\
\hline$T_{\text {neigh_1 }}$ & $\begin{array}{l}\text { Neighbour 1's living room } \\
\text { temperature }\end{array}$ & {$\left[{ }^{\circ} \mathrm{C}\right]$} \\
\hline$T_{\text {neigh_2 }}$ & $\begin{array}{l}\text { Neighbour 2's living room } \\
\text { temperature }\end{array}$ & {$\left[{ }^{\circ} \mathrm{C}\right]$} \\
\hline$C_{\mathrm{w}_{-} \mathrm{i}_{1} 1}$ & Inner thermal mass of zone 1 & {$[\mathrm{~J} / \mathrm{K}]$} \\
\hline$C_{\mathrm{w} \_ \text {o_ } 1}$ & Outer thermal mass of zone 1 & {$[\mathrm{~J} / \mathrm{K}]$} \\
\hline$P_{\text {exch_1 }}$ & $\begin{array}{l}\text { Heat transfer between inner and } \\
\text { outer thermal mass of zone } 1\end{array}$ & {$[\mathrm{~W}]$} \\
\hline$P_{\text {vent_1 }}$ & $\begin{array}{l}\text { Heat transfer through ventilation in } \\
\text { zone } 1\end{array}$ & {$[\mathrm{~W}]$} \\
\hline$P_{\text {sol_1 }}$ & Solar heat gain in zone 1 & {$[\mathrm{~W}]$} \\
\hline$P_{\text {transm_1 }}$ & $\begin{array}{l}\text { Heat transfer between outer } \\
\text { thermal mass of zone } 1 \text { and } \\
\text { ambient\&ground }\end{array}$ & {$[\mathrm{W}]$} \\
\hline$P_{\text {exch_12 }}$ & $\begin{array}{l}\text { Heat transfer between zone } 1 \text { and } \\
\text { zone } 2\end{array}$ & {$[\mathrm{~W}]$} \\
\hline$P_{\text {exch_13 }}$ & $\begin{array}{l}\text { Heat transfer between zone } 1 \text { and } \\
\text { zone } 3\end{array}$ & {$[\mathrm{~W}]$} \\
\hline$P_{\text {neigh_1 }}$ & $\begin{array}{l}\text { Heat transfer between zone } 1 \text { and } \\
\text { neighbour } 1\end{array}$ & {$[\mathrm{~W}]$} \\
\hline$P_{\text {neigh_2 }}$ & $\begin{array}{l}\text { Heat transfer between zone } 1 \text { and } \\
\text { neighbour } 2\end{array}$ & {$[\mathrm{~W}]$} \\
\hline$U A_{\text {exch_1 }}$ & $\begin{array}{l}\text { Heat transfer coef. between inner } \\
\text { and outer thermal mass of zone } 1\end{array}$ & {$[\mathrm{~W} / \mathrm{K}]$} \\
\hline$U A_{\text {vent_1 }}$ & $\begin{array}{l}\text { Heat transfer coef. through } \\
\text { ventilation in zone } 1\end{array}$ & {$[\mathrm{~W} / \mathrm{K}]$} \\
\hline$U A_{\text {transm_1 }}$ & $\begin{array}{l}\text { Heat transfer coef. between outer } \\
\text { thermal mass of zone } 1 \text { and } \\
\text { ambient }\end{array}$ & {$[\mathrm{W} / \mathrm{K}]$} \\
\hline$U A_{\text {transm_g }}$ & $\begin{array}{l}\text { Heat transfer coef. between outer } \\
\text { thermal mass of zone } 1 \text { and ground }\end{array}$ & {$[\mathrm{W} / \mathrm{K}]$} \\
\hline$U A_{\text {exch_12 }}$ & $\begin{array}{l}\text { Heat transfer coef. between zone } 1 \\
\text { and zone } 2\end{array}$ & {$[\mathrm{~W} / \mathrm{K}]$} \\
\hline$U A_{\text {exch_13 }}$ & $\begin{array}{l}\text { Heat transfer coef. between zone } 1 \\
\text { and zone } 3\end{array}$ & {$[\mathrm{~W} / \mathrm{K}]$} \\
\hline$U A_{\text {neigh_1 }}$ & $\begin{array}{l}\text { Heat transfer coef. between zone } 1 \\
\text { and neighbour } 1\end{array}$ & {$[\mathrm{~W} / \mathrm{K}]$} \\
\hline$U A_{\text {neigh_2 }}$ & $\begin{array}{l}\text { Heat transfer coef. between zone } 1 \\
\text { and } 2\end{array}$ & {$[\mathrm{~W} / \mathrm{K}]$} \\
\hline$g_{\text {window }}$ & Glass neighbour transmittance & {$[-]$} \\
\hline$f_{\text {shading }}$ & Total shading factor & {$[-]$} \\
\hline$Q_{\text {sol }}$ & $\begin{array}{l}\text { Solar radiation on horizontal } \\
\text { surface }\end{array}$ & {$\left[\mathrm{W} / \mathrm{m}^{2}\right]$} \\
\hline$A_{\text {window_1 }}$ & Total glass area of zone 1 & {$\left[\mathrm{~m}^{2}\right]$} \\
\hline$f_{\text {solar fraction }}$ & $\begin{array}{l}\text { Fraction to convert solar radiation } \\
\text { on a horizontal surface to the } \\
\text { vertical surface of the } \\
\text { corresponding facade }\end{array}$ & {$[-]$} \\
\hline
\end{tabular}

